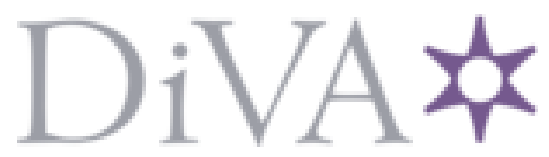

http://www.diva-portal.org

This is the published version of a paper published in Vehicle System Dynamics.

Citation for the original published paper (version of record):

Drugge, L., Larsson, T., Stensson, A. (2000)

Modelling and simulation of catenary-pantograph interaction.

Vehicle System Dynamics, 33(suppl): 490-501

Access to the published version may require subscription.

N.B. When citing this work, cite the original published paper.

Permanent link to this version:

http://urn.kb.se/resolve?urn=urn:nbn:se:bth-11315 


\title{
Modelling and simulation of catenary-pantograph interaction
}

\author{
LARS DRUGGE, TOBIAS LARSSON and ANNIKA STENSSON
}

\begin{abstract}
SUMMARY
Modelling and simulation of the dynamic behaviour of catenary-pantograph interaction is an important part when assessing the capability of a current collection system for railway traffic. The large variation in infrastructure characteristics in different countries and railway companies, different types of traffic, designs of pantographs etc. makes it almost impossible to develop a final simulation model of such a system. Instead, it would be favourable to have a tool that has the ability to set up models of such systems, choose relevant detail of the models, run simulations and finally visualise the results. To make the tool useful for engineers, design experts as well as simulation experts, the functionality of the tool must be worked out. Aspects on computer simulation such as developed models, simulation methods and computer tools are presented. The aim is to develop a scenario that considers different designs, models, solution methods and user levels. The scenario focuses on how to structure the use of simulation of dynamics in catenary-pantograph development. A scenario is sketched built on different user levels, a modular structure and a structure for information management.
\end{abstract}

\section{INTRODUCTION}

The capability of a current collection system depends on an interaction between locomotive, pantograph and catenary system, see Figure 1. When developing such systems, it is important to have the ability to predict the dynamic performance of the system.

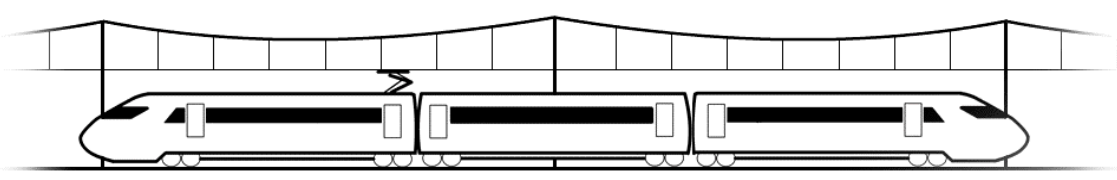

Fig. 1. A train with its catenary-pantograph system.

These types of systems have been analysed by several engineers during the last decades. Depending on factors such as the actual configuration of the systems, available information, desired accuracy of simulation results, simulation methods etc. different types of models are applicable.

${ }^{1}$ Division of Computer Aided Design, Luleå University of Technology, SE-971 87 Luleå, Sweden. 
The large variation in infrastructure characteristics in different countries and railway companies, different designs of pantographs, different types of traffic (types of vehicles, running speed etc), makes it almost impossible to develop a final simulation model of the system. It is also difficult to recommend models for specific cases, since the relevant model depend on access to information, wanted accuracy of the results, accessible resources etc. Instead, it would be favourable to have a tool that has the ability to set up models of the system, choose relevant detail of the models, perform simulations and finally visualise the results. Then the user can validate the created model for the specific application.

To make the developed tool useful for engineers, design experts as well as simulation experts, the functionality of the computer tool must be worked out. For example, it would be favourable if the engineer does not need to have specific knowledge about the details in the different models and solution methods.

The work focuses on how to structure the use of simulation of dynamics in catenary-pantograph development. The aims are to give a basis for the development of such a tool and to be a ground for further discussions. The use of simulation of catenary-pantograph systems, aspects on computer simulation such as developed models, simulation methods and existing computer tools are presented. Prerequisites that could be put on a simulation tool with the described functionality are considered. A scenario is sketched built on different user levels, a modular structure and a structure for the information management.

\section{SIMULATION OF CATENARY-PANTOGRAPH DYNAMICS}

With respect to the dynamic behaviour, the catenary and pantograph are vital components in current collection systems for trains. The pantograph mechanism is mounted on the roof of the train and often consists of a head assembly and a variable height frame assembly. The frame assembly raises the head assembly into forced contact with the catenary system. A simple catenary system, for example, consists of a contact wire suspended from a catenary wire via an arrangement of droppers, see Figure 1. The catenary wire is linked directly to the supporting structure, while the contact wire is linked to the support via steady arms.

During the life cycle of a product the same questions occur repeatedly, see Figure 2. For example, upper arrows could be the question "will there be any risk for failure?" and lower arrows could be the question "do contact loss occur?". To answer the questions it is advantageous to use mathematical simulation models.

\section{Simulation processes in product development}

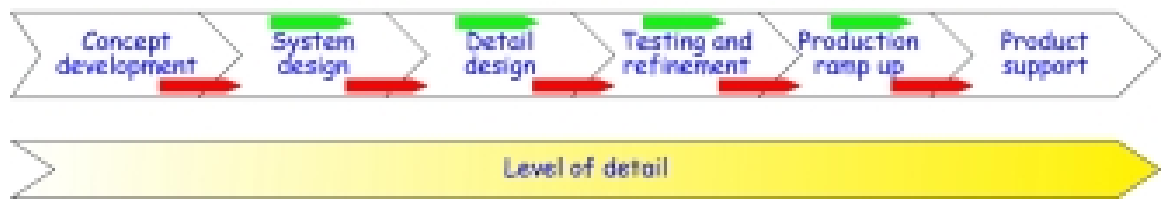

Fig. 2. Questions and corresponding simulation activities occur repeatedly during the product development process. 
In the early stages fast modelling and comparative analyses are crucial in order to evaluate different design concepts. The accessible information is often insufficient and unstructured and the time frame for decisions limited. At later stages, the product is defined with higher level of detail, and accurate analysis is increasingly important. In these phases, better information is often available in terms of experimental data from prototype testing. This makes it possible to verify the developed simulation models. After verification, the simulation model can be used to estimate effects of changes in the system.

To make well-founded decisions early in the product development process simulation is advantageous. It also gives the designer a possibility to test more ideas in shorter time. With a computer model of the system, it is easy to make changes that would be very time consuming to do with physical prototypes.

There are also financial incitements to continuously improve the performance of for example catenary systems, which have a long life length. The issue is to use existing designs as far as possible as well as having well motivated arguments for making changes.

Simulation is a necessity to test unrealistic or dangerous situations as for example when increasing speed of trains. The risk of product failure and hereby following consequences such as person injuries, material damages, delay in traffic etc. makes it very expensive to test new ideas. Simulation should be used in order to make a reasonable judgement of the product performance in advance.

In full-scale field experiments many parameters vary at the same time, for example wind loads, temperatures, air humidity, and the state of vehicles and infrastructure. By developing models and study effects of changes in different parameters during controlled conditions, one can locate resources where they are most beneficial.

This leads to different demands on the solution methods and level of detail of the model. A more detailed model is often related to a less flexible solution method, while parameter data for a model that resemble the physical design might be easier to determine. Motives for chosen simulation model and solution method are for example the access to information, wanted accuracy of the results, allowed simplifications as well as accessible resources in terms of time, money and personnel. Knowledge and skill of personnel is important, both when choosing simulation tool and the level of detail of the model. When developing models it is also important to keep track on the actual size and variation of system parameters since a model never is better than its input.

Traditionally, large companies with special technical analysis departments have used simulation. Since the simulation techniques are becoming mature, the technique is available for use by others. Simulation is a necessary and effective tool for the company to use in order to make cost effective and secure decisions. The current status is that simulations are often carried out after the product is developed, in order to explain suddenly upcoming phenomena. At this point, a lot of time and money has been spent on developing the product and changes, such as switching to another concept, are very expensive.

Simulation involves the use of a methodology, see Figure 3. The methodology is similar independent of the level of detail of the model and the chosen simulation method. This makes it easier to reuse earlier work and easier to document the performed work. The products are often complex and include many degrees of 
freedom as well as non-linear characteristics. This implies that it only occasionally is possible to find analytical solutions to the equations of motion. Often, one must use numerical experiments where the motion of the developed models is calculated for different situations. It is often suitable to connect the definition of the dynamic system to a CAD-tool, where it is easy to define geometry, calculate mass and inertia, position of joints and loads etc. Three-dimensional CAD models are also suitable for visualisation of the design, for investigation of aerodynamic forces, animation of the dynamic behaviour etc.

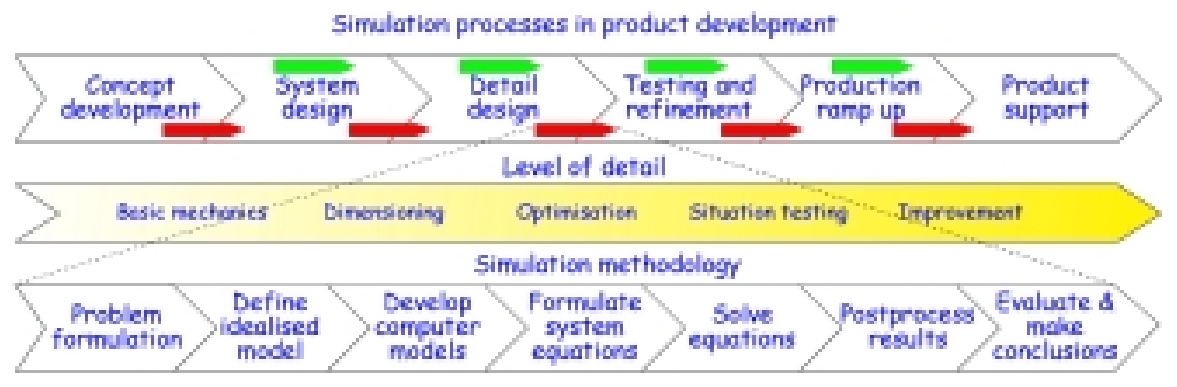

Fig. 3. Simulation methodology in different phases of the development process.

\section{MODELLING}

The variety of designs of current collection systems is large. Depending on country, railway company and type of traffic different designs of pantographs and catenary systems are used. There are both low voltage DC and high voltage AC powered systems. Many different pantograph designs have evolved, such as single-stage or dual-stage pantographs based on a symmetric or asymmetric configuration, new concepts of telescopic type as well as proposals for active control concepts [1-4]. There are also different designs of catenary systems to consider [3-6]. Three common catenary types are the simple catenary, the stitched catenary and the compound catenary. For each catenary type, a variety of designs of components like droppers, steady arms etc. exists.

Research has been made to understand and improve the performance of the catenary-pantograph system by mathematical modelling for many years. Simplified analytical models of the system have been used in order to determine critical speeds and to study the influence of principal system parameters [7]. The system is modelled as a single degree-of-freedom system for studying the response to parametric excitation by the variable stiffness of the catenary.

Often the pantograph dynamic behaviour is linearised around some operational height resulting in a few degree-of-freedom mass-spring-damper model representation [8-11]. Geometrically nonlinear two-dimensional models have also been developed. Some models study the motion of the system from a side view [12-14] while others are defined in a plane transverse to the motion of the train [15]. Lately, three-dimensional pantograph models are used [16-19]. To evaluate proposals of new active pantograph concepts, simple few degrees of freedom models of the pantograph are often used [10,20-22]. 
The catenary has been modelled using different approaches. One degree-offreedom mass-spring-damper system models with varying stiffness and mass [23], and string models with elastic foundation [24] have been used. Models with twoand three-dimensional representation of the catenary are most common [8-10,1819,25]. Important characteristics of the system are, for example, nonlinear droppers, longitudinal motion of the wire due to the sag, zigzag effects, damping of the system, and at high speed the bending stiffness of the wire.

Solution methods such as the finite difference method [8], finite element method [10,18-19], modal analysis [11,14,21] and multibody dynamics [16-17] have been used.

Some models developed for simulation of catenary-pantograph dynamics are illustrated in Figure 4.

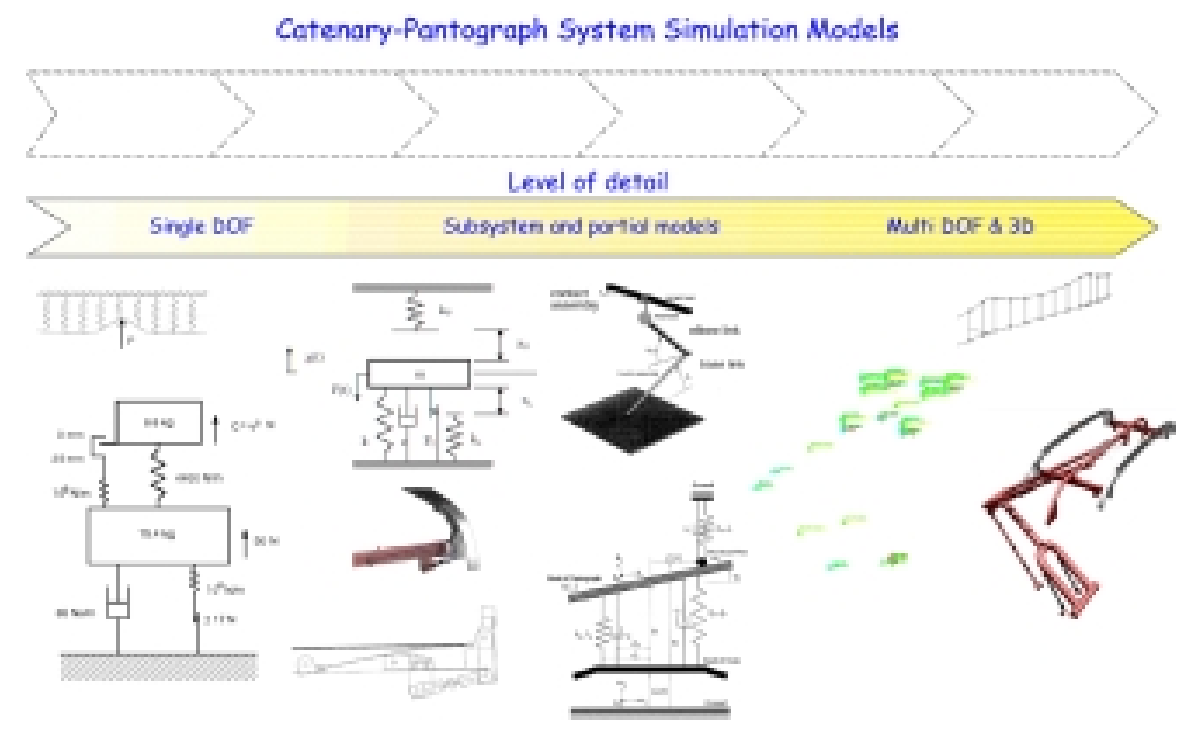

Fig. 4. Examples of models for catenary-pantograph system simulation [26].

Historically, people needing to determine the dynamic behaviour of catenarypantograph systems developed their own computer codes to solve their specific problems [8-11,13-14]. Some of these codes have been further developed into suites of programs for simulation of different designs and a large variety of conditions.

The last decades rapid development and implementation of computer based tools have had great impact on the product development processes. To facilitate the use of modelling of catenary-pantograph dynamics in these tools pre- and postprocessors have been developed. Reinbold et al. [19] have developed a simulation tool, FAMOS, for the static and dynamic simulation of the catenarypantograph system. The tool is based on the finite element program ABAQUS. A toolbox for pantograph testing and design, PANDA, is presented in Balestrino et al. [27]. The PANDA program was developed using MATLAB. The pantograph structure in the program is built out of predefined library models. Veitl et al. [16] have developed simulation models for the design of new pantograph systems 
using solid models, created in ProEngineer, with interface to the multibody system program SIMPACK. The catenary is modelled in the specialised catenary tool PrOSA. The two programs are coupled via co-simulation. In order to enable the use of simulation of catenary-pantograph dynamics in the design process at the Swedish National Rail Administration, a simulation tool has been developed [26]. The tool is primarily designed to be an aid for the development of catenary equipment.

\section{COMPUTER TOOL PREREQUISITES}

The prerequisites on a computer tool for simulation of catenary-pantograph dynamics can be derived from the presented modelling and simulation aspects, and be divided into three categories; modelling prerequisites, simulation prerequisites and usability prerequisites. Below are examples from these categories listed.

\subsection{Modelling prerequisites}

General prerequisites:

$\checkmark$ Consistent method for set up of simulation models

$\checkmark$ Techniques to set up models of combinations of substructures

$\checkmark$ Consistent method for model reduction

$\checkmark$ Database structure of simulation models

For every line:

$\checkmark \quad$ Type of catenary system

$\checkmark$ Number of sections

$\checkmark$ Number of spans

$\checkmark \quad$ Type of and distance between pantographs

$\checkmark$ Velocity of train

For every span:

$\checkmark$ Span length

$\checkmark$ System height

$\checkmark$ Stagger

$\checkmark$ Wire height

$\checkmark$ Data of wires and clamps

$\checkmark$ Position of droppers

$\checkmark$ Curve radius and direction

$\checkmark$ Superelevation of track

$\checkmark \quad$ Type of supporting structure

$\checkmark$ Discrete features such as section insulators, section overlaps etc.

$\checkmark$ External loading

For every pantograph:

$\checkmark$ Kinematics

$\checkmark \quad$ Mass and inertia properties

$\checkmark$ Characteristics for springs, dampers, bump stops etc. 
$\checkmark \quad$ Friction properties

$\checkmark$ Static, aerodynamic and control forces

\subsection{Simulation prerequisites}

$\checkmark \quad$ Variety of simulation situations

$\checkmark$ Different solution methods

$\checkmark$ Models with different level of detail

$\checkmark$ Type of wanted results

$\checkmark$ Automated parameter variations

$\checkmark$ Optimisation

$\checkmark$ Co-simulation possibilities

$\checkmark$ Possibilities to connect to hardware-in-the-loop (HIL)

\subsection{Usability prerequisites}

$\checkmark$ Presentation of results

$\checkmark$ Possibilities for visualisation

$\checkmark$ Libraries with common designs

$\checkmark$ Re-use of models

$\checkmark$ Platform for continuous improvement

$\checkmark$ Information exchange through neutral format

$\checkmark$ Trace-ability and documentation

$\checkmark$ User-friendly environment

\section{SCENARIO}

Based on the presented aspects on computer simulation, modelling and computer tool prerequisites, a scenario is sketched. The aim of the scenario is to be a ground for further discussions and to give a basis for a development of such a tool. The scenario is based on different user levels, a modular structure of simulation models and a structure for information management.

To make the tool useful for engineers, design experts and simulation experts, an approach with different user levels with enhanced functionality is suggested. In Figure 5, a proposed functionality of the different user levels is presented. Briefly, the engineer wants to analyse existing designs in different situations, the design expert want to modify or develop new designs whereas the simulation expert want to modify or develop new simulation models and solution methods. As an example, the simulation expert develops a parameterised simulation model of a pantograph suspension that the suspension design expert can use. Then the design expert can combine his domain specific knowledge with simulation of the dynamic behaviour and hereby develop a better product. The different user levels have access to different functionality within the tool. The same person can also choose between the different user levels depending on the task that is to be solved. To illustrate the different needs of functionality of the user levels, examples from different process levels are presented. 


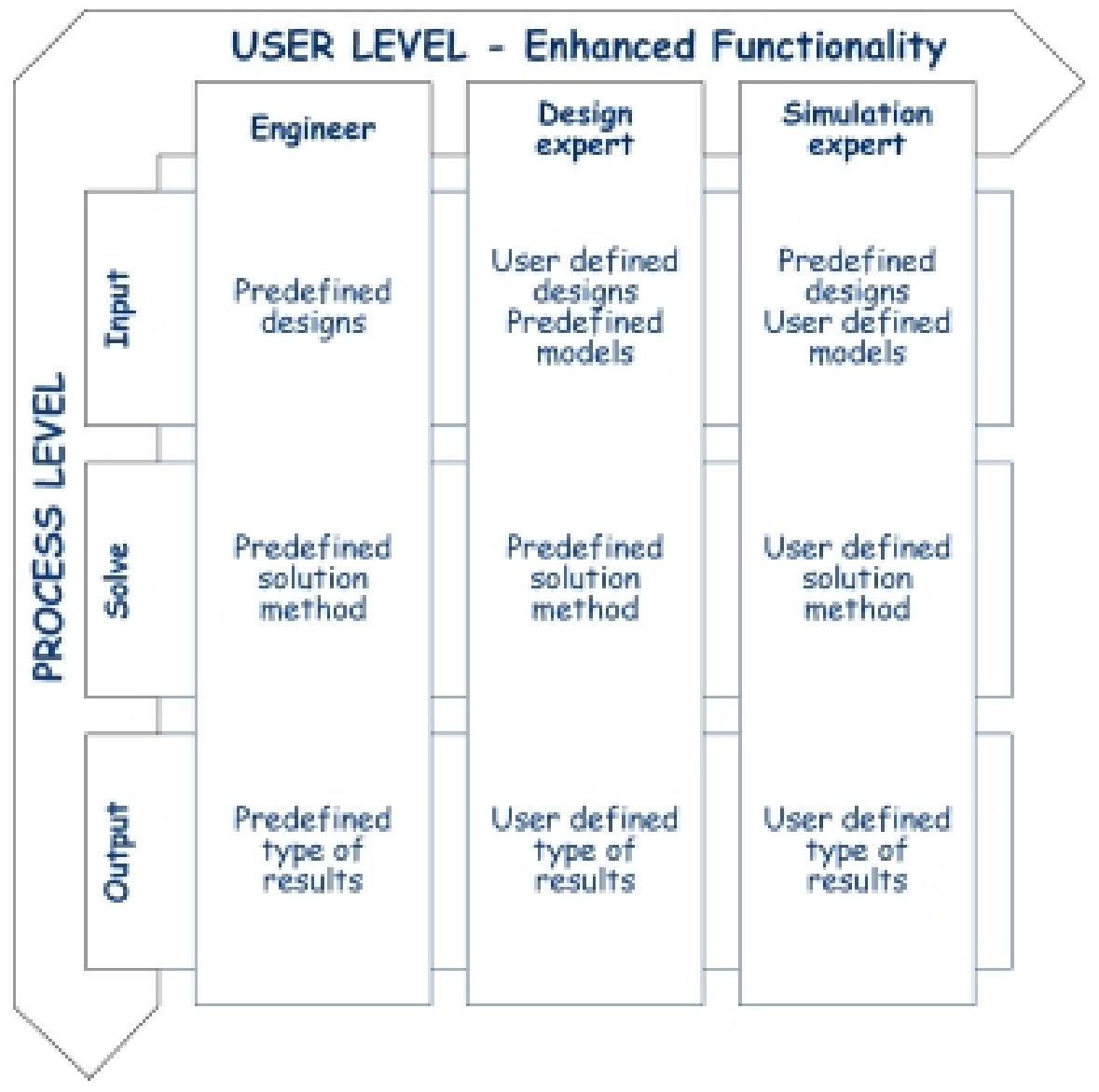

Fig. 5. Illustration of the user structure in the scenario.

Suppose an engineer wants to investigate the system performance of a new line or the influence of new running conditions on an existing line. He uses the tool on a regular basis and has not specific knowledge of mathematical modelling. Different designs of catenary systems and pantographs are defined and can be chosen from a library. Studied situations could for example be effects of changing number of and distances between pantographs, train speed, static uplift force, running on straight or curved track. Depending on the desired accuracy of the results different accuracy levels can be chosen. The accuracy levels are connected to the level of detail of the simulation model, the studied situation and the solution method. Model reduction techniques are used to transform actual system data into suitable model format. While running a predefined solution method, parameters to be varied in the solve process level could be the desired simulation time and requests of results.

A design expert might want to develop a new design of current collection system. He could start from an existing design and modify it, or create a design from scratch. Variables could for example be design of droppers, tension in wires, wire characteristics, design of registration arms, wire gradients, section overlaps 
and section insulators. The characteristics of the pantograph can be defined from either a library of different pantograph types or by a user defined design. Variables could be kinematics, mass distribution, spring and damping characteristics, bump stops etc. The design expert implements new designs into the tool and makes them accessible to the other user levels.

The simulation expert develops and verifies simulation models of different parts in the current collection system. He could either start with modifying an existing model or create a new one. The specific geometric design is chosen from the library of existing designs. New models are implemented into the tool by the simulation expert and he makes them accessible to the other user levels.

The people that use the tool do not necessary have to be in the same organisation or at the same place. The design and simulation experts could be persons located on a company that develops pantographs. They can export their designs and models to be implemented into the tool. Hereby, an engineer at, for example, the Swedish National Rail Administration can simulate the behaviour of the total system by choosing the desired catenary and pantograph designs. The models could be available as black boxes without insight, because structures or parameters of the model might be company sensitive. They can also be grey boxes where parameter variation is permitted according to model developer, or models with full insight.

By choosing desired accuracy level, the system will choose a relevant model and related solution method based on defined relations and rules. Predefined types of results could for example be plots of contact force and pantograph trajectory, statistics such as maximum and minimum contact force, standard deviation, percentage of contact loss and animations etc. The user-defined type of results could for example be plots of detection of impacts, phase plane plots of main suspensions and tension in a certain dropper. Possibilities to import for example experimental data to compare with simulated results should be included.

To structure the tool a modular approach is suggested. The modular approach gives the opportunity to reduce time in the product development process and will make it easier to develop new generations of products [28,29]. By building the full system simulation model out of a library of subsystems, many combinations would be possible. When developing the simulation models it is important to define the interfaces, or boundaries, of the model. The advantage of this approach is that it is possible to replace an old module with a newly developed one without changing the individual specification of the other modules. If the different developed subsystems are integrated into a common simulation environment it is possible for the subsystem designer to see the impact of his development to the total system behaviour without having the knowledge to build and simulate the total system. This approach makes parallel development of subsystem models, or simulation modules, possible and creates the opportunity to test different design solutions with as little effort as possible. A catenary-pantograph simulation module structure could look like Figures 6-7. 


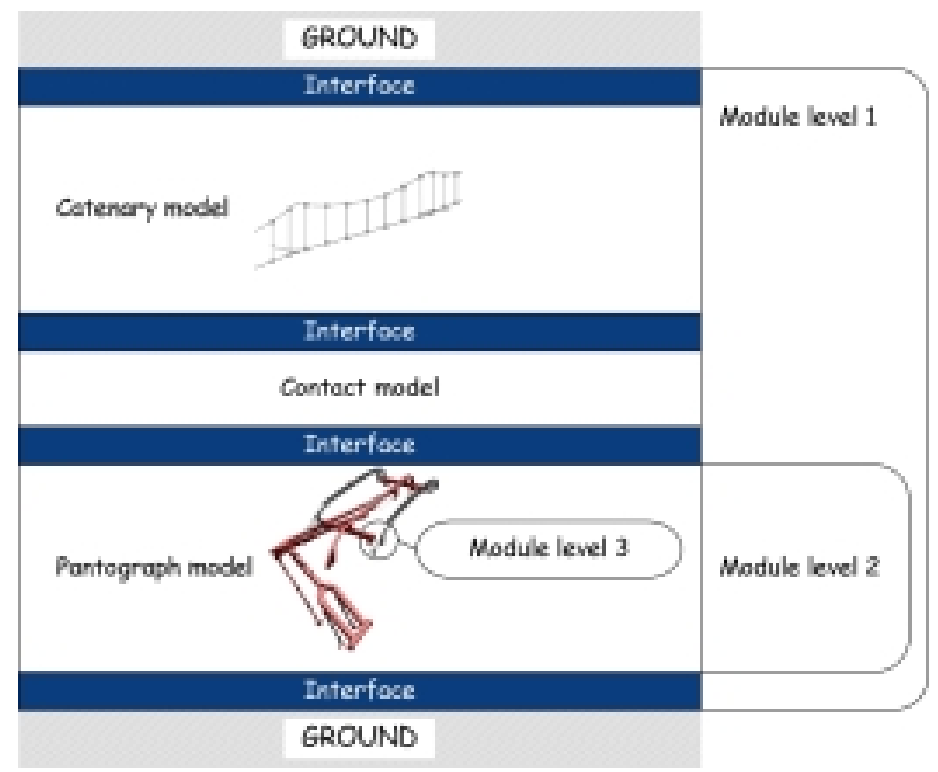

Fig. 6. Module structure for a catenary-pantograph system.

To be able to organise the information in an effective way, an information management structure based on a database [30] and a neutral format, such as STEP, is suggested. A neutral data format makes it possible to let the model data be available to different types of software for the calculation of the dynamics such as FEA, MBS, CFD, CACE etc. This also makes the system less sensitive to chosen software suppliers and makes it possible to choose the best software for the specific application. In addition, the information from CAD-programs or special purpose programs can be transferred via the neutral format to the system information database. This in order to minimise the risk for information loss and regeneration of information.

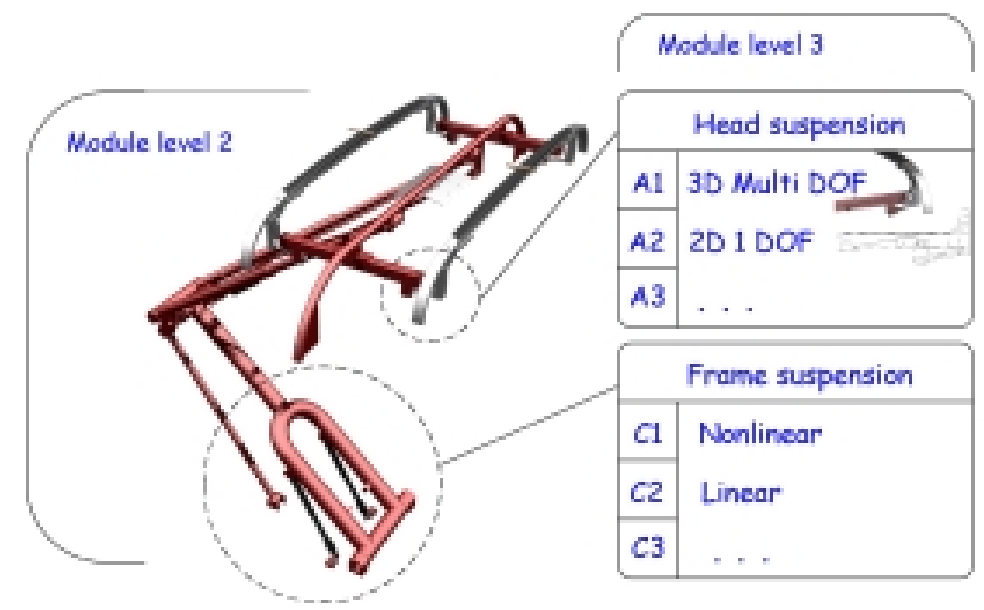

Fig. 7. Illustration of simulation module structures for a pantograph. 


\section{CONCLUSIONS}

This work concerns computer simulation of dynamics in catenary-pantograph development. Aspects on computer simulations such as developed models, simulation methods and computer tools are presented. A scenario that considers different designs, models, solution methods and user levels has been proposed. A modular structure of the tool and a structure for information management are advised.

The proposed tool is considered to consist of two parts. A computer tool for handling of the modelling and simulation, and a methodology for how to use the tool in the catenary-pantograph product development process. The modular approach makes it possible to implement company specific models as well as simulation models from subcontractors. The tool is to be seen as a platform for continuos development. A platform that will make the catenary-pantograph development more effective.

\section{ACKNOWLEDGEMENTS}

The authors wish to acknowledge the financial support of The Swedish National Rail Administration and The Swedish Engineering Design Research and Education Agenda, ENDREA.

\section{REFERENCES}

1. Bartels, S., Versuchstromabnehmer für ICE, Elektrische Bahnen eb, 86 (9), 1988, pp. 290-296.

2. Coxon, D.J., Gostling, R.J. \& Whiteland, K.M., Evolution of a Simple High-Performance Pantograph, Railway Gazette International, 1980, pp. 44-47.

3. Belyaev, I.A., Vologine, V.A. \& Freifeld, A.V., Improvement of Pantographs and Catenaries and Method of Calculating their Mutual Interactions at High Speeds, Rail International, 1977, pp. 309-328.

4. Poetsch, G., Evans, J., Meisinger, R., Kortüm, W., Baldauf, W., Weitl, A. \& Wallaschek, J., Pantograph/Catenary Dynamics and Control, Vehicle System Dynamics, 28, 1997, pp. 159195.

5. Bauer, K.H., Seifert, R. \& Kießling, F., Weiterentwicklung der Oberleitungen für Höhere Fahrgeschwindigkeiten, ETR 38, 1989, no. 1-2, pp. 59-66.

6. Tessun, H., Shaping up for the future - overhead contact lines for train speeds of up to 400 $\mathrm{km} / \mathrm{h}$, ABB Review 3, 1995, pp. 31-38.

7. Wu, T. X. \& Brennan, M.J., Basic Analytical Study of Pantograph-catenary System Dynamics, Vehicle System Dynamics, 30, 1998, pp. 443-456.

8. Hobbs, A.E.W., Accurate Prediction of Overhead Line Behaviour, Railway Gazette International, Sept. 1977, pp. 339-343.

9. Manabe, K., Measure to Multiple Pantographs of High Speed Train Operation, Japanese Railway Engineering, 109, 1989, pp.11-14.

10. Diana, G., Bruni, S., Collina, A., Fossati, F. \& Resta, F., High Speed Railways: Pantograph and Overhead Lines Modelling and Simulation, Computers in Railways VI, Ed. B. Mellitt et al., WIT Press, Southampton, 1998, pp. 847-856.

11. Levy, S., Bain, A. \& Leclerc, E.J., Railway Overhead Contact Systems, Catenary-Pantograph Dynamics for Power Collection at High Speeds, Journal of Engineering for Industry, nov. 1968, pp. 692-700.

12. Eppinger, S.D., O'Connor, D.N., Seering, W.P. \& Wormley, D.N., Modelling and Experimental Evaluation of Asymmetric Pantograph Dynamics, Journal of Dynamic Systems, Measurements, and Control, Vol. 110, 1988, pp. 168-174.

13. Nowak, B. \& Link, M., Zur Optimierung der Dynamischen Parameter des ICEStromabnehmers durch Simulation der Fahrdynamik, VDI Berichte 635, 1987, pp. 147-166. 
14. Renger, A., Berechnung des Dynamischen Verhalten von Oberleitungs-kettenwerk und Stromabnehmer, VDI Berichte 820, 1990, pp. 141-154.

15. Yagi, T., Stensson, A. \& Hardell, C., Simulation and Visualisation of the Dynamic Behaviour of an Overhead Power System with Contact Breaking, Vehicle System Dynamics 25, 1996, pp. 31-49.

16. Veitl, A. Baldaulf, W, \& Kortüm, W., Simulation als Werkzeug der Auslegung neuer Stromabnehmer, Eisenbahningenieur 49, 2, 1998, pp. 70-73.

17. Larsson, T. \& Drugge, L., Dynamic Behaviour of Pantographs due to Different Wear Situations, Computers in Railways VI, Ed. B. Mellitt et al., WIT Press, Southampton, 1998, pp. 869-880.

18. Lesser, M., Karlsson, L. \& Drugge, L., An Interactive Model of a Pantograph-catenary System, Vehicle System Dynamics, Supplement 25, 1996, pp. 397-412.

19. Reinbold, M. \& Deckart, U., FAMOS - Ein Programm zur Simulation von Oberleitungen und Stromabnehmern, ZEV + DET Glasers Annalen 120, 6, 1996, pp. 239-243.

20. Galeotti, G., Galanti, M., Magrini, S. and Toni, P., Servo Actuated Railway Pantograph for High-speed Running with Constant Contact Force, Proc. Instn. Mech. Engrs. 207, 1993, pp. 37-49.

21. O’Connor, D.N., Eppinger, S.D., Seering, W.P. \& Wormley, D.N., Active Control of a HighSpeed Pantograph, Journal of Dynamic Systems, Measurements, and Control, Vol. 119, 1997, pp. 1-4.

22. Thompson, A.G. \& Davis, B.R., An Active Pantograph with Shaped Frequency Response Employing Linear Output Feedback Control, Vehicle System Dynamics 19, 1990, pp.131149.

23. Kumezawa, I., Overhead Wire for High Speed Electric Railway Traction, Bulletin of the International Railway Congress Association, Electric Traction on the Railways, Vol. XIII, No. 1,1962 , pp. 1-23.

24. Gilbert, G. \& Davies, H.E.H., Pantograph Motion on Nearly Uniform Railway Overhead Line, Proc. IEE, vol. 113, no. 3, 1966, pp. 485-492.

25. Resch, U. \& König, A., Simulation der Kontaktkraft zwischen Fahrdraht und Schleifleiste des Systems Oberleitung/Stromabnehmer, VDI BERICHTE NR. 1219, pp. 321-329, 1995.

26. Research Project, Methods and Tools for Analysis of Pantograph-Catenary Dynamics, Luleå University of Technology, Sweden.

27. Balestrino, A., Bruno, O., Landi, A. \& Sani L., PANDA: A friendly CAD Tool for Pantograph Design and Testing, Computers in Railways VI, Ed. Mellitt et al., WIT Press, 1998, pp. 817 826.

28. Erixon, G., Modular Function Deployment - A Method for Product Modularisation, Doctoral Thesis, Assembly Systems Division, Royal Institute of Technology, Sweden, 1998.

29. Andreasen, M. M., Reduction of the Complexity of Product Modelling by Modularization, Proceedings of Produktmodeller '98, November 10-11, Linköping 1998, pp. 39-53.

30. Hardell, C., Stensson, A., Jeppsson, P., A Relational Database for General Mechanical Systems. In Computational Dynamics in Multibody Systems. Eds. M. Pereira and J. Ambrosio. Kluwer Academics pp. 49-59, 1995. 